\title{
Editorial: The Effect of Climate Change across Ocean Regions
}

\author{
Ove Hoegh-Guldberg ${ }^{1,2,3 *}$ and Elvira S. Poloczanska ${ }^{1,4}$ \\ ${ }^{1}$ The Global Change Institute, University of Queensland, St. Lucia, QLD, Australia, ${ }^{2}$ ARC Centre for Excellence in Coral Reef \\ Studies, University of Queensland, St. Lucia, QLD, Australia, ${ }^{3}$ School of Biological Sciences, University of Queensland, St. \\ Lucia, QLD, Australia, ${ }^{4}$ Integrative Ecophysiology, Alfred Wegner Institute for Polar and Marine Research, Bremerhaven, \\ Germany
}

Keywords: corals, deep sea, cold water, climate change, symbiotic, mass coral bleaching, ocean acidification, ocean warming

\section{Editorial on the Research Topic}

\section{The Effect of Climate Change across Ocean Regions}

According to the consensus of the Fifth Assessment Report (AR5) of the Intergovernmental Panel on Climate Change (IPCC, 2014), conditions within Earth's ocean are changing at rates that are greater than any of other time during the past 65 million years. As a result, major changes have begun to occur in ocean systems that have serious consequences for geophysical, ecological, and human systems. This research topic expands on discussions held as part of AR5 on past, present and future changes across ocean regions (Figure 1), drawing on literature published since the AR5 cut-off dates for literature (March to October 2013, depending on IPCC Working Group) as well as new analyses.

The papers in this collection present a global overview of the geophysical to ecological changes (Howes et al.) in the following sub-regions: sub-tropical gyres (Signorini et al.), the Mediterranean semi-enclosed sea (Marbà et al.), the North Atlantic High latitude spring bloom system (Sundby et al.), eastern boundary upwelling systems (García-Reyes et al.). Risks to specific ecosystems are presented by Hoegh-Guldberg et al.(warm- and cold-water coral reefs) and Steckbauer et al.(the benthic ecosystem in the EBUE along the coast of Chile). Boyd presents a modeling exercise of impacts on the ocean "biological pump" which has consequences for the ocean carbon cycle. Poloczanska et al. focus on distribution shifts of species as a response to climate change and synthesize information across the ocean regions while Weatherdon et al. provide an update of the assessment on social and economic impacts arising from changes in ocean ecosystems.

Changes in ocean primary production are explored by Boyd using a 1-D model to investigate the impacts of changing temperature on components of the "biological pump," (the roles of marine microbes in moving carbon from surface waters into deep ocean). The study shows that climatedriven shifts in surface and subsurface structure of plankton communities reduce the efficiency of the biological pump, thus an important feedback loop to the global carbon cycle. The potential of ocean warming to impact the global carbon cycle is also highlighted in the contribution of Signorini et al. who analyzed the trends in chlorophyll- $a$ and derived net primary production in the surface waters of the five sub-tropical ocean gyres: the North Pacific, South Pacific, Indian Ocean, North Atlantic, and South Atlantic. These gyre systems occupy around $40 \%$ of the surface of the Earth so although they are oligotrophic (low biomass and low productivity) they make an important contribution to the global carbon cycle given their immense size. In all gyres, significant downwards trends in chlorophyll- $a$ (except South Pacific) and net primary production were found, measured over 1998-2013. 


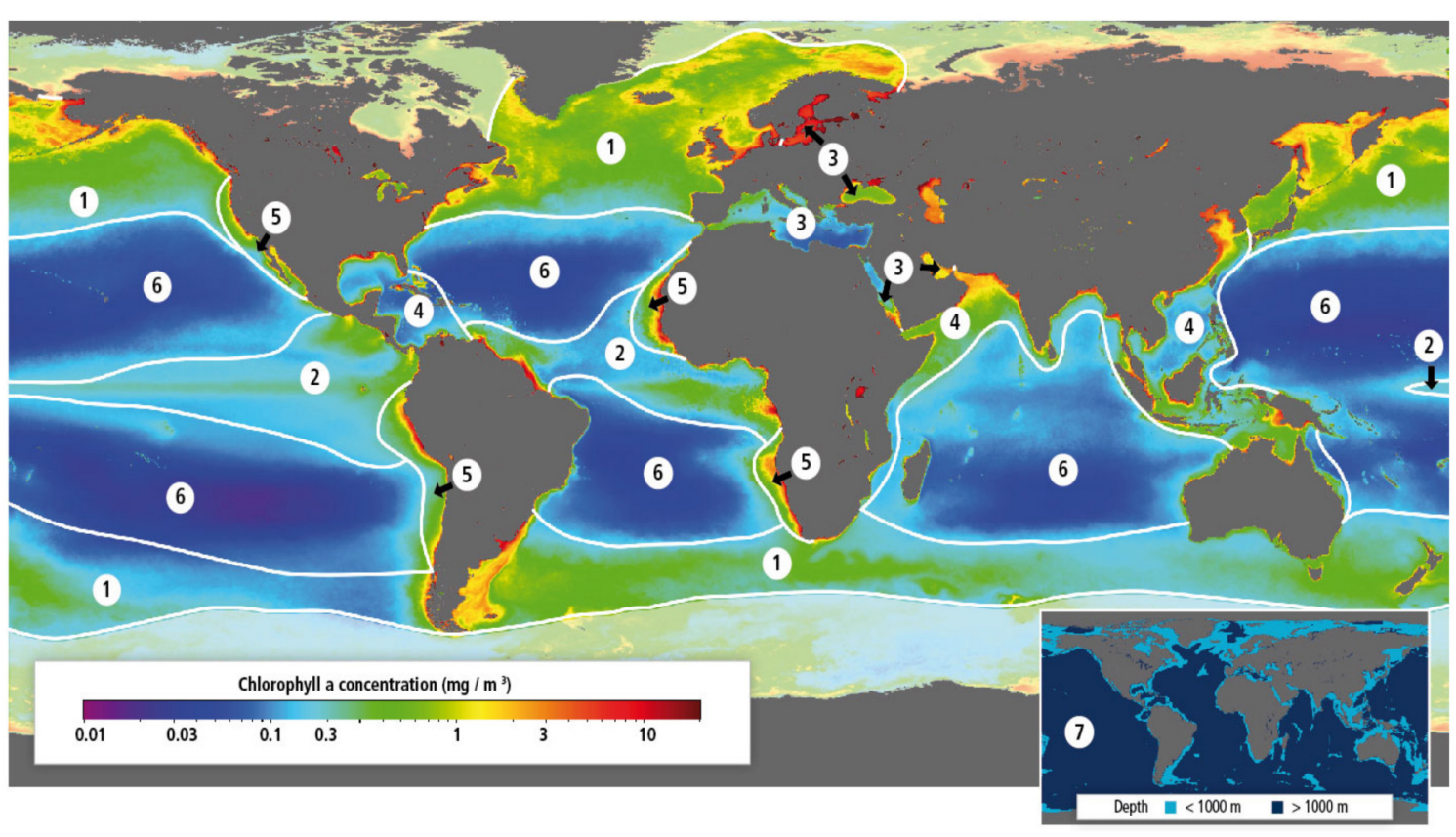

FIGURE 1 | Separation of the world's oceans into seven major sub-regions (excluding an eighth area, Polar Oceans; white shaded area). The chlorophyll-a signal measured by SeaWIFS and averaged over the period from Sep 4, 1997 to 30 Nov 2010 (NASA) provides a proxy for differences in marine productivity. Ecosystem structure and functioning, as well as key oceanographic features, provided the basis for separating the Ocean into the sub-regions shown. The map insert shows the distribution of the Deep Sea (DS) habitat (>1,000 m; Bathypelagic and Abyssopelagic habitats combined).

García-Reyes et al. synthesize the current state of knowledge of the dynamics of the Eastern Boundary Upwelling Systems (EBUE) and provide evidence that coastal upwelling-favorable changes in the poleward portions of these systems (with the exception of the Canary EBUE) have intensified. This synthesis also considers future effects on coastal biogeochemistry and concludes that, although confidence in the projected changes is currently low, observed decreases in $\mathrm{pH}$ and oxygen concentrations in the upper waters of EBUE are expected to continue. These are highly productive ecosystems and hence changes in their physical and biogeochemical properties are likely to have ecological impacts with severe economic and social consequences for coastal fisheries and communities. The ecological repercussions are highlighted in the paper by Steckbauer et al., who experimentally show that the combined effects of decreased $\mathrm{pH}$ (ocean acidification) and decreased oxygen concentration enhance negative impacts on invertebrates from the coastline of Chile in the Humboldt Current EBUE. However, the authors point out that the invertebrates are likely to be adapted to short-term exposures to these stressors.

The compound risks from warming temperatures and ocean acidification were reviewed Hoegh-Guldberg et al. with respect to cold- and warm-water corals. Their assessment highlights the high vulnerability of these ecosystems to climate change, and warns that warm-water coral reefs may be eliminated by midcentury without urgent and drastic mitigation. This consensus stemming from the AR5 is emphasized the recent catastrophic heating events driving mass coral bleaching and mortality in many parts of the world including the Indo-Pacific and Caribbean, and key sites such as the Great Barrier Reef (Hughes et al., 2017). Marbà et al. synthesize evidence of the effects of warming temperatures on the Mediterranean Sea ecosystems and show widespread changes in migration, abundance, survival, and phenology of species, among other factors, which are particularly evident during marine heat waves. The study highlights the high sensitivities of many Mediterranean species to warming, which are likely due to direct metabolic impacts of temperature and indirect impacts on nutrient availabilities. Sundby et al. and Poloczanska et al. also focus on distribution shifts on marine species. Sundby et al. look at the north Atlantic HLSBS where warming has been rapid, and consider influence of climate variability, such as the North Atlantic Oscillation and Atlantic Multidecadal Oscillation on ecosystem attributes including phytoplankton and zooplankton production and fish stock productivity. In particular, they focus on observations of, and the potential for, climate-driven distribution shifts of key species in the region drawing out the underlying mechanisms. They present evidence that there are limits to poleward migration of temperate species into the polar region under future climate change. The transition to extreme seasonality in the light cycle at latitudes strongly influences primary production and north of the "critical latitudes" $\left(63-68^{\circ} \mathrm{N}\right)$ where life cycles adapted for low food availability during long, dark winters are required. Poloczanska et al. show graphically how regional warming and light seasonality can influence the potential for shifts the 
TABLE 1 | Relationship between area (millions $\mathrm{km}^{2}$ ), primary productivity, and fish catch (as millions of tons $\mathrm{yr}^{-1}$ ) for the period $1970-2006$ for each ocean sub-region shown in Figure $\mathbf{1}$ (numbers in Figure $\mathbf{1}$ correspond to numbers in this table).

\begin{tabular}{|c|c|c|c|c|c|}
\hline \multicolumn{2}{|l|}{ Area } & \multirow{2}{*}{$\begin{array}{l}\text { Description } \\
\text { From } 35^{\circ} \mathrm{N} \text { and } 35^{\circ} \mathrm{S} \text { to the edge of the winter ice. Strong seasonal } \\
\text { cycle of primary productivity that is nutrient limited at times and which } \\
\text { becomes more pronounced toward higher latitudes where primary } \\
\text { production shifts to a single peak during early spring and decreases to } \\
\text { near zero in winter (numbered references) }\end{array}$} & \multirow{2}{*}{$\begin{array}{c}\text { Area (\%) } \\
\begin{array}{c}10.6 \\
14.4\end{array}\end{array}$} & \multirow{2}{*}{$\begin{array}{c}\begin{array}{c}\text { Primary } \\
\text { productivity (\%) }\end{array} \\
22.6 \\
20.4\end{array}$} & \multirow{2}{*}{$\begin{array}{c}\begin{array}{c}\text { Fisheries } \\
\text { productivity (\%) }\end{array} \\
29.6 \\
6.8\end{array}$} \\
\hline $\begin{array}{l}\text { 1. High Latitude } \\
\text { Spring Bloom } \\
\text { Systems (HLSBS) }\end{array}$ & $\begin{array}{l}\text { Northern Section } \\
\text { Southern Section }\end{array}$ & & & & \\
\hline 3. Semi Enclosed & eas (SES) & $\begin{array}{l}\left.\text { Defined here as large landlocked seas ( }>200,000 \mathrm{~km}^{2}\right) \text { with single } \\
\text { narrow passageways }(<120 \mathrm{~km}) \text { includes Arabian Gulf, Red, } \\
\text { Mediterranean, Black, and Baltic seas }\end{array}$ & 1.1 & 2.3 & 3.3 \\
\hline \multicolumn{2}{|c|}{ 4. Western Boundary Systems (WBS) } & $\begin{array}{l}\text { Include diverse marine ecosystems that are influenced by different } \\
\text { location-specific oceanographic processes and primary productivity } \\
\text { values. Like the EBUE, light is abundant although nutrients may be } \\
\text { restricted spatially and temporally by a number of different factors (e.g., } \\
\text { stratification, coastal run-off) }\end{array}$ & 6.2 & 10.6 & 28 \\
\hline \multicolumn{2}{|c|}{ 6. Subtropical Gyres (STG) } & $\begin{array}{l}\text { Found in all three oceans and exhibit low productivity due to warm and } \\
\text { highly stratified water columns which restricts nutrient supply to } \\
\text { euphotic layer ("ocean nutrient deserts") }\end{array}$ & 41.0 & 22.0 & 8 \\
\hline \multicolumn{2}{|c|}{ 7. Deep Ocean (DO) } & $\begin{array}{l}\text { Defined here as habitats below } 1,000 \mathrm{~m} \text { representing the largest habitat } \\
\text { on Earth. Despite its large size, our understanding of the deep ocean is } \\
\text { minimal. Interacts strongly with the upper ocean through the } \\
\text { sedimentation of biogenic material, remineralization, vertical mixing, } \\
\text { upwelling, downwelling, and vertical migrations (including ontogenetic) }\end{array}$ & 88.0 & 0 & 0.5 \\
\hline
\end{tabular}

The top three bars (sub-regions HLSBS-North, CBS, and EBUE) cover 19\% of the world oceans' area and provide $76 \%$ of the world's fish catches. Both Figure 1 and Table 1 modified from Hoegh-Guldberg et al. (2014).

distribution of species across latitudes. In the tropics, species may need to shift distributions large distances to track optimal temperatures but will experience little change in light seasonality, while at high latitudes, a short shift in distance can mean exposure to very different light seasonality. Poloczanska et al. also assess the evidence for climate-driven distribution shifts across ocean regions and discuss the factors facilitating or limiting responses.

Howes et al. present a synthesis of literature from physics and chemistry to ecology. In particular, they present updates for the evidence of impacts and vulnerabilities across taxonomic groups: microbes, macroalgae, and seagrasses, and animals, to changes in temperature, dissolved oxygen, and ocean acidification. Weatherdon et al. review the literature and expand discussions to consider the impacts on the goods and services provided by marine ecosystems such as the risks from ocean acidification to shellfish fisheries and aquaculture, and the impacts of warming on the distributions of fish stocks and fisheries catches. They consider regional impacts on tropical, temperature and subtropical and polar fisheries. They assess the recent evidence for risks to coastal tourism, human health and food security from climatedriven shifts in species distributions and other climate change impacts.
Overall, we hope that the group of papers that we have drawn together here will be useful for understanding the current and unprecedented changes that are occurring in the world's oceans. In many cases, the observed phenomena are in the earliest stages of being understood, suggesting that the literature and understanding in each of these fundamental areas is set to grow rapidly over the coming years.

\section{AUTHOR CONTRIBUTIONS}

All authors listed have made a substantial, direct, and intellectual contribution to the work, and approved it for publication.

\section{FUNDING}

This writing project was supported by the Australian Research Council (to OH-G) as an ARC Laureate Fellow. The authors are also grateful to the Centre Scientifique De Monaco for hosting $\mathrm{OH}-\mathrm{G}$ during the development of this editorial.

\section{ACKNOWLEDGMENTS}

The editors are grateful to be contributions made by the many authors involved in this project. 


\section{REFERENCES}

Hoegh-Guldberg, O., R., Cai, E. S., Poloczanska, P. G., Brewer, S., Sundby, K., et al. (2014). "The ocean," in Climate Change 2014: Impacts, Adaptation, and Vulnerability. Part B: Regional Aspects. Contribution of Working Group II to the Fifth Assessment Report of the Intergovernmental Panel of Climate Change, eds V. R. Barros, C. B. Field, D. J. Dokken, M. D. Mastrandrea, K. J. Mach, T. E. Bilir, M. Chatterjee, K. L. Ebi, Y. O. Estrada, R. C. Genova, B. Girma, E. S. Kissel, A. N. Levy, S. MacCracken, P. R. Mastrandrea and L. L. White (Cambridge University Press: Cambridge; New York, NY).

Hughes, T. P., Kerry, J., Álvarez-Noriega, M., Álvarez-Romero, J., Anderson, K., Baird, A., et al. (2017). Global warming and recurrent mass bleaching of corals. Nature 543, 373-377. doi: 10.1038/nature 21707
IPCC (2014). “Climate Change 2014: Synthesis Report,” in Contribution of Working Groups, I., II and III to the Fifth Assessment Report of the Intergovernmental Panel on Climate Change, eds Core Writing Team, R. K. Pachauri, and L. A. Meyer (Geneva: IPCC), 151.

Conflict of Interest Statement: The authors declare that the research was conducted in the absence of any commercial or financial relationships that could be construed as a potential conflict of interest.

Copyright $\odot 2017$ Hoegh-Guldberg and Poloczanska. This is an open-access article distributed under the terms of the Creative Commons Attribution License (CC BY).

The use, distribution or reproduction in other forums is permitted, provided the original author(s) or licensor are credited and that the original publication in this journal is cited, in accordance with accepted academic practice. No use, distribution or reproduction is permitted which does not comply with these terms. 